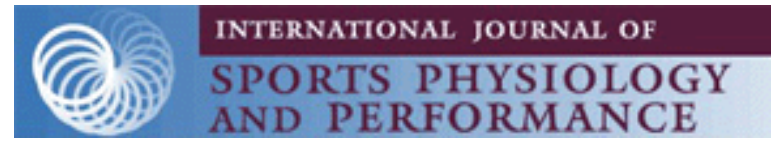

\title{
Influence of Maturation Status on Eccentric Hamstring Strength Improvements in Youth Male Soccer Players following the Nordic Hamstring Exercise
}

\begin{tabular}{|c|c|}
\hline Journal: & International Journal of Sports Physiology and Performance \\
\hline Manuscript ID & IJSPP.2019-0184.R2 \\
\hline Manuscript Type: & Original Investigation \\
\hline $\begin{array}{l}\text { Date Submitted by the } \\
\text { Author: }\end{array}$ & 05-Oct-2019 \\
\hline Complete List of Authors: & $\begin{array}{l}\text { Drury, Ben; Hartpury University , Applied Sport Sciences } \\
\text { Green, Thomas; St Peters RC High School, Physical Education } \\
\text { Ramírez-Campillo, Rodrigo; Universidad de Los Lagos, ; Rodrigo Ramirez } \\
\text { Moran, Jason; University of Essex, School of Sport, Rehabilitation and } \\
\text { Exercise Sciences }\end{array}$ \\
\hline Keywords: & $\begin{array}{l}\text { adolescent, strength, resistance training, physical performance, } \\
\text { pediatrics, kinetics }\end{array}$ \\
\hline
\end{tabular}

\section{SCHOLARONE \\ Manuscripts}


1 Purpose: This study examined the effects of a 6-week nordic 2 hamstring exercise (NHE) program in youth male soccer players of 3 less mature (Pre-Peak Height Velocity [PHV]) or more mature 4 (Mid/Post-PHV) status. Methods: Forty-eight participants were 5 separated into Pre-PHV (11.0 $\pm 0.9 y r s)$ or Mid/Post-PHV (13.9 \pm 6 1.1) groups and further divided into experimental (EXP) and 7 control (CON) groups with eccentric hamstring strength assessed 8 (Nordbord) both pre and post the training program. Participants in 9 the EXP groups completed a periodised NHE program performed 10 once or twice weekly over a 6-week period. Results: The NHE 11 programme resulted in moderate and small increases in relative eccentric hamstring strength (N.kg-1) in the Pre-PHV EXP $(d=$ $0.83[0.03-1.68])$ and Mid-PHV EXP $(d=0.53[-0.06-1.12])$ groups respectively. Moderate increases in the same measure were also seen in the between-group analyses in the Pre-PHV $(d=1.03$ $[0.23-1.84])$ and Mid-PHV groups $(d=0.87[0.22-1.51])$, with a greater effect observed in the former. Conclusion: The results from this study demonstrate that a 6-week NHE program can improve eccentric hamstring strength in male youth soccer players with less mature players achieving mostly greater benefits. The findings from this study can aid in the training prescription of the NHE in youth male soccer players. 
47

48

49

50

51

52

53

54

55

56

57

58

59

60

61

62

63

64

65

66

67

68

69

70

71

72

73

74

75

76

77

78

79

80

81

82

83

84

85

86

87

88

89

90

91

\section{Introduction}

To support the athletic development of youth soccer players and to reduce their injury potential, the safest and most successful training methods should be incorporated to help youth players compete at the highest level. ${ }^{1}$ Additionally, it has been suggested that due to the developmental nature of youth soccer players and their desire to achieve professional status, it is important to reduce the occurrence of injury. ${ }^{2}$ Indeed, it has recently been reported that injury risk increases with age in young soccer players from as early 7 years old. ${ }^{3}$ In particular, to support the aforementioned within soccer, the FIFA 11+ program has been developed to support the prevention of lower extremity injuries for players aged 14 years and above. ${ }^{4}$ Furthermore, evidence of the efficacy of using the FIFA $11+$ to reduce the incidence of injury in male youth soccer players aged between 14-19 years has previously been demonstrated. 5 Therefore, the inclusion of specific injury prevention strategies to mitigate injury risk in youth soccer players is required.

A key component of the FIFA $11+$ is the emphasis placed upon the development of eccentric hamstring strength via performing the nordic hamstring exercise (NHE). Its inclusion as an injury prevention exercise is supported due to its ability to greatly reduce hamstring injuries. ${ }^{6}$ For example, in elite soccer players, high levels of eccentric hamstring strength has been shown to reduce the risk of hamstring injury. ${ }^{5}$ Furthermore, the specific inclusion of the NHE has been shown to reduce hamstring injury risk in male adult soccer players. ${ }^{7,8,9}$ However, although the inclusion of the NHE is recommended within the FIFA 11+ for all playing levels, direct evidence supporting the beneficial effects of the NHE in increasing eccentric hamstring strength in male youth soccer players under the age of 14 years has not been reported. Although eccentric hamstring strength was not directly measured, it has recently been demonstrated that a 5-week training period with two sessions per week of the FIFA 11+ warm up improved body stability in male 10 -year-old soccer players. ${ }^{10}$ The limited information that exists pertaining to the benefits of the inclusion of the NHE in developing eccentric hamstring strength in youth soccer players is surprising. Indeed, this becomes further apparent when considering that it has been reported that practitioners working in elite English male youth soccer academies have indicated that players aged 13-16 are at the greatest risk of injury and that a lack of eccentric hamstring strength is amongst the most important injury risk factors. ${ }^{11}$ 
Despite the efficacy of the NHE in adult athletes, its inclusion within youth athletes is not be commonplace. For example, a previous iteration of FIFA 11+, simply entitled '11', excluded the exercise on the basis that it was considered too intense for young and inexperienced athletes. ${ }^{12}$ In contradiction to this though, a significant increase of $12.6 \%$ in eccentric hamstring strength has been reported in male basketball players aged between 10 to 12 years following the performance of a 5-week NHE training program. ${ }^{13}$ Therefore, although the inclusion of the NHE in male youth soccer players warm-up protocols may aid in the prevention of injuries, the specific improvements in eccentric hamstring strength within this population is unknown. Moreover, this notion is further confounded by the individual's maturation status, which can influence performance capacities in youth. ${ }^{14}$ For instance, in youth soccer it has been shown that maturity status in male youth soccer players influences the outcomes from training programs such as sprinting ${ }^{15,16}$ and plyometrics ${ }^{16,17}$ with changes attributed to differences such as muscle size, co-ordination, and hormonal profile. ${ }^{18}$ Therefore, the present study investigated the effects of a NHE program on improvements in eccentric hamstring strength in youth male soccer players, comparing responses in prepubertal (Pre-PHV) and Mid/Post-pubertal (Mid/Post-PHV) male participants. Based on previous findings of strength and power training in youth athletes, we hypothesised that greater improvements in eccentric hamstring strength would be observed in the more mature participants.

\section{Methods \\ Design}

A randomized controlled trial was conducted to compare the effects of six weeks of NHE training in male youth soccer players. To calculate the sample size, statistical software (GPower; University of Dusseldorf, Dusseldorf, Germany) was used. Given the study design (4 groups, 2 repeated measures), the effect size = 1.05 based on a previous research investigating the effects of lower limb strength training in Pre-PHV and Mid/Post-PHV young male athletes, ${ }^{19}$ alpha-error $<0.05$, the nonsphericity correction $€=1$, the correlation between the repeated measures $=0.5$, and a desired power $(1-\beta$ error $)=0.80$, the total sample size resulted in a minimum of 8 participants required in each condition. Subsequently, a total of forty-eight participants were recruited from the soccer team and randomly allocated (www.randomizer.org) into two experimental (EXP) groups $(\mathrm{n}=8$ $\mathrm{x}$ Pre-PHV and $\mathrm{n}=16 \mathrm{x} \mathrm{Mid} / \mathrm{Post}-\mathrm{PHV}$ ) and two control (CON) groups $(\mathrm{n}=11 \times$ Pre-PHV and $\mathrm{n}=13 \times \mathrm{Mid} /$ Post-PHV). The 
experiment took place within the competitive season and participants continued to participate in their regular soccer training programs performed twice per week for a period of 6 weeks; however, the EXP groups additionally performed a NHE program prior to the beginning of each soccer training session. All participants were tested for eccentric hamstring strength before and after the 6-week programme, by the same investigators who were not blinded to the groups. During the previous two weeks prior to pre-testing occurring, four separate familiarization sessions were conducted for all participants to ensure technical proficiency of performing the NHE. A maximum of three to five repetitions of the NHE were performed in each session and this was overseen by the lead researcher. Each familiarization session took place at the club's training facility prior to their soccer training session and was separated by a minimum of $48 \mathrm{hrs}$.

\section{Participants}

Initially, seventy-six male youth soccer players volunteered to participate in the study. However, after completion of the experiment, twenty-eight participants had to be removed from the study because they did not follow the targeted adherence rate, were released by the club or did not present for post-training tests. No participants were excluded from the study due to injury. Subject characteristics per maturity level and training group are presented in Table 1. All participants were free from lower-limb musculoskeletal injuries prior to the start of the study, were physically active, had $\geq 2$ years of soccer experience, participating regularly in training at their club. Participants were not involved with any formalised strength and conditioning programmes and had no prior experience of performing the NHE. Parental informed consent was obtained for participants as they were under the age of 18 years. The University Research Committee provided ethical approval prior to testing beginning and the study was completed in accordance with the Declaration of Helsinki.

$$
\text { ***Insert Table } 1 \text { near here }{ }^{* * *}
$$

\section{Procedures}

Eccentric hamstring strength was tested both before and after the training intervention. These tests were performed a minimum of $48 \mathrm{~h}$ after the most recent training session or match to allow appropriate recovery. Prior to each testing session, the participants completed the same standardised warm up which was subsequently completed prior to all training sessions. The warm up lasted approximately 10 minutes and included low intensity jogging, change of direction drills, lower-limb dynamic stretching 
and jumping based tasks. All participants in the EXP and CON groups performed soccer specific training with the club, twice per week, on a Monday and Wednesday evening from $6 \mathrm{pm}-9 \mathrm{pm}$. A weekly competitive match was scheduled on a Saturday.

\section{Anthropometrics}

Before testing started, data on age, stature and body mass were recorded to assert each player's current maturation status. Body mass measurements were also collected following completion of the training program prior to follow-up-testing occurring. Participants' standing and seated height were measured using a stadiometer (Seca Model 213, Birmingham, England), to the nearest $0.1 \mathrm{~cm}$. Body mass was measured, using a calibrated electronic scale (Seca Model 813, Birmingham, England), to the nearest $0.1 \mathrm{~kg}$. To estimate maturity status, these anthropometric measurements were taken and entered into an equation to predict maturity offset, ${ }^{20}$ within an error of \pm 1 year, $95 \%$ of the time. The assessment is a non- invasive and practical method of predicting years from PHV as a measure of maturity offset. Maturation groups were divided in accordance to previous recommendations with Pre-PHV participants categorized as $<-2$ years from PHV, whilst Mid/Post-PHV were between -1 to +2.5 years from PHV. ${ }^{21}$

\section{Eccentric Hamstring Strength}

The NHE was performed on the NordBord apparatus (Nordbord, Vald Performance, Australia) which has been shown to be a reliable device to assess eccentric hamstring strength (IC = $0.83-0.90$ and $\mathrm{CV} \%=5.8 \%-8.5 \%){ }^{22}$ Similarly, we have found values for between session relative reliability for male youth soccer players from our lab $(\mathrm{CV} \%=6.1-7.4 \%)$. All baseline and follow-up testing occurred at the same location and facility which was the team's training centre. For the assessment of eccentric hamstring strength, participants were instructed to kneel on the padded part of the NordBord and were positioned with their ankles secured with padded hooks, which were attached to load cells. Participants' position was altered so that ankles would be perpendicular to the lower leg and the hooks were positioned superior to the lateral malleolus. The NHE was performed using an eccentric muscle action of the knee flexors and participants were instructed to gradually lower the upper body trying to resist the movement by contracting the hamstrings and keeping the trunk and hips held in a neutral position throughout. Participants were encouraged upright posture with their spine and pelvis in a neutral position. Participants' arms were flexed at the elbow joints such that the palms of the hands were facing forward at the level of the shoulder joints. The participants were allowed to use their arms in 
the final stages of the movement to buffer the fall as they approached the ground. For the ascent, the research personnel assisted the participants back to the starting position. Due to the inherent maturation-related differences in strength that existed between the experimental groups, we elected only to include relative peak force as an outcome measure, instead of absolute peak force which would have favoured the Mid-PHV groups in the analyses. Relative peak force normalised to body mass $\left(\mathrm{N} . \mathrm{kg}^{-1}\right)$ for each leg of the three trials was recorded in newton's (N) using LabChart 7.3 (AD Instruments, New South Wales, Australia) and subsequently analyzed in a pre-designed excel spreadsheet with the average of each limb from the three trials added together and divided by two to provide a bilateral score which was used for data analysis.

\section{Training Programs}

The NHE program lasted six weeks (Table 2). To be included in the final analyses, participants were required to complete at least $85 \%$ of the total training sessions (nine of eleven scheduled sessions). This adherence threshold was chosen to reflect a recent experiment in male youth soccer players that also used a similar training program duration. ${ }^{23}$ Furthermore, greater benefits in strength have been reported when compliance over this threshold has been achieved. ${ }^{24}$ To monitor the compliance to the NHE protocol, participants' attendance rates at the training sessions were recorded for each individual session by a strength and conditioning coach using a registration form which was subsequently confirmed by the respective age group coach. To ensure the correct execution of the NHE each training group was allocated a strength and conditioning coach to oversee the training program, which helped provided the participants with instructions regarding their technique where necessary. Each session was separated by a minimum of $48 \mathrm{hrs}$. The NHE program was immediately performed after the warm-up.

\section{***Insert Table 2 near here***}

The structure of the NHE program was adapted from previous recommendations with the volume of training progressively increasing weekly. ${ }^{9}$ Coaching cues and instructions used throughout the training program were the same as those provided throughout the aforementioned NHE testing procedures. Identical weekly increases in NHE training volume was performed for both EXP groups and each participant alternated between performing one set and assisting their partner in doing the same with approximately 60-90 seconds of inter-set rest provided. 
Whilst the EXP group completed the NHE program, the CON group participated in low intensity passing drills until the main training session begun in which both groups completed the same soccer training. No formal sprint training was scheduled within the training sessions throughout the experiment period as it has been recently reported that improvements in eccentric hamstring strength in adolescents can be improved to a similar extent via sprint training or the NHE. ${ }^{25}$

\section{Statistical Analysis}

Initial analyses were performed using SPSS) (version 23, IBM Corp., Armonk, NY, USA). The Shapiro-Wilk test was conducted to test for normality in each variable and this condition was satisfied $(P<0.05)$. Independent samples t-tests were used to test for any differences between each maturity groups EXP and CON conditions for anthropometric measures and initial eccentric hamstring strength. Thereafter, magnitude-based inferences were used to quantify within- and between-group differences from baseline to follow-up, and to compare changes in experimental and control conditions respectively. Uncertainty in the effect sizes $(d)$ was represented by $90 \%$ confidence limits. ${ }^{26}$ Effect sizes were interpreted using previously outlined ranges $[(<0.2=$ trivial, $0.2-$ $0.6=$ small, $0.6-1.2=$ moderate, $1.2-2.0=$ large, $2.0-4.0=$ very large, $>4.0=$ extremely large) ${ }^{27}$ An effect size of 0.2 was considered the 'smallest worthwhile difference'. ${ }^{26}$ The scale for interpreting the probability that the result was significant was as follows: almost certainly not $=<1 \% ; 1-5 \%=$ very unlikely; $5-25 \%$ $=$ unlikely; possibly $=25-75 \%$; likely $=75-95 \%$; very likely $=95$ $99.5 \%$; most likely $>99.5 \%$ and was calculated using an online spreadsheet. $^{28}$ Differences were considered unclear if the confidence interval overlapped thresholds for substantial positive and negative values. Data are presented as mean \pm SD.

\section{Results}

No significant differences $(\mathrm{p}>0.05)$ between the Pre-PHV and Mid/Post-PHV experimental groups and their respective control group for anthropometric and initial eccentric hamstring measures were found. Effect sizes and their descriptors and likelihood estimates of beneficial effects for within and between group analyses are shown in Tables 3 and 4, respectively.

$$
\text { ***Insert Tables } 3 \text { and } 4 \text { near here*** }
$$

Within-group analyses showed an increase in relative peak force in both EXP groups although this was improved to a greater extent in Pre-PHV compared to Mid/Post-PHV ( $d=0.83$ vs. 0.53$)$. 
Both Pre-PHV and Mid/Post-PHV CON groups demonstrated trivial increases.

\author{
Between-group analyses revealed moderate increases in \\ both maturity groups with the larger effect size being seen in the \\ Pre-PHV group $(d=1.03$ vs. 0.87$)$.
}

\title{
Discussion
}

The aim of this study was to examine the effects of a NHE program on improving eccentric hamstring strength in youth male soccer players of different maturation status, comparing Pre-PHV and Mid/Post-PHV players. The within-group analyses revealed that the inclusion of the NHE increased relative eccentric hamstring strength in both Pre-PHV and Mid/Post-PHV groups, although larger effects were observed in the Pre-PHV group. Additionally, both control groups yielded no changes in eccentric hamstring strength values from pre to post testing. To the authors' knowledge, this is the first study to demonstrate the effectiveness of the NHE in developing eccentric hamstring strength in male youth soccer players and to specifically compare the influence of different maturation status on this outcome.

The Pre-PHV and Mid/Post-PHV EXP groups increased relative peak force by $\sim 19 \%$ and $\sim 10 \%$, respectively. These findings are similar to those previously reported in studies following a NHE program in which increases of absolute and normalised eccentric hamstring strength have been reported to be $\sim 11 \%$ and $\sim 14 \%$ in well-trained soccer players following a 10 week (250-286 repetitions) or 4-week (162 repetitions) NHE training program, respectively. ${ }^{29,30}$ Similarly, in amateur male soccer players, a 12 week (642 repetitions) NHE program performed either before or after training resulted in increases in eccentric hamstring strength of $\sim 12 \% .^{31}$ Furthermore, in male adults with no prior experience of performing the NHE, similar to the participants used in this study, increases of $\sim 15 \%$ in eccentric hamstring strength has been shown following a 6-week (340 repetitions) NHE program. ${ }^{32}$ However, we do acknowledge that such comparisons in the changes in eccentric hamstring strength in our study should be taken with caution due to the differences in the assessment method used._Nonetheless, the current findings suggest that a well-structured NHE programme conducted over a 6-week training period is sufficient to elicit beneficial changes in eccentric hamstring strength in male youth soccer players, without causing injury. 
To the authors' knowledge, only one previous study has investigated the effects of the NHE in male youth athletes with male youth basketball players, aged 10-12 years, increasing their eccentric hamstring strength. ${ }^{13}$ The participants in that study completed 232-304 repetitions over a 5-week period which resulted in a $12.6 \%$ increase in eccentric hamstring strength. Although our study resulted in similar increases, these were achieved with a total of 162 repetitions. Therefore, it appears that increases in eccentric hamstring strength via the completion of use of NHE training program in youth male soccer players can be achieved via relatively modest training volumes. However, whether such improvements can be made with lower training volumes within this population remains to be seen as it has been recently demonstrated that in elite youth soccer players a low volume NHE programme, including just 10 repetitions per week, is sufficient to elicit benefits in eccentric hamstring strength. ${ }^{33}$ In particular, our finding of increased strength in the Pre-PHV EXP group is interesting as, to date, some doubt over the appropriateness of this exercise for use in a prepubertal population had been expressed. ${ }^{12}$ However, in this study we demonstrated performance gains that were also achieved without any occurrence of musculoskeletal injuries. Participants who withdrew from the study, due to failing to meet the agreed training adherence rate, did so due to other issues, rather than factors such as muscle soreness that have been thought to be associated with the use of eccentric exercise in younger individuals. Indeed, conceptions such as these would not be supported by current evidence in any case. ${ }^{34,35}$

Our results also showed that although the NHE program resulted in improvements in eccentric hamstring strength in both EXP groups, the magnitude of the effects were greater in Pre-PHV than in Mid/Post-PHV (Table 3). We chose relative strength as an outcome measure as higher body mass and absolute strength can influence total eccentric hamstring strength scores in the NHE exercise. ${ }^{36}$ Relatedly, our finding that pre-pubertal boys responding more positively to resistance training than post-pubertal boys is not entirely in agreement with previous research in which it has been demonstrated that more mature males experience greater improvements in strength and power-related characteristics than less mature males. ${ }^{19,37,38}$ However, it may indicate the importance in ingraining relative strength as a base for absolute strength in less mature individuals from an early age. From an exercise prescription standpoint, a potential explanation for the differences in responses between the EXP groups may be due to the possible inadequate stimulus of the NHE program for the Mid/Post-PHV group. For example, whilst both groups within this study had no 
412

413

414

415

416

417

418

419

420

421

422

423

424

425

426

427

428

429

430

431

432

433

434

435

436

437

438

439

440

441

442

443

444

445

446

447

448

449

450

451

452

453

454

455

456 prior experience of the NHE, the greater chronological age of the Mid/Post-PHV group may have acted as a surrogate of training age, whereby older players have adapted positively from a longer training history. ${ }^{39}$ Indeed, in adolescents it has recently been reported that eccentric hamstring strength can be improved to a similar extent via sprint training or the NHE. ${ }^{25}$ Therefore, whilst high-speed sprint training was avoided during the training program, the Mid/Post-PHV group players' higher training age and exposure to training stimuli, such as sprinting, may have meant that the NHE program produced a lower adaptation than that seen in the Pre-PHV group. Consequently, Mid/Post-PHV athletes may require an altered training prescription.

In light of the aforementioned, the programming of the NHE during growth and maturation may require further specificity to optimise its effectiveness. For example, due to only bodyweight being used as the loading strategy in this study, it could be speculated that this may have inadvertently provided a lower training stimulus for the Mid/Post-PHV group. This is because performance of the NHE is largely body mass dependent and it has been predicted that soccer players should be expected to achieve eccentric hamstring strength scores $(\mathrm{N})$ of $4 \times \mathrm{BM}(\mathrm{kg})+26.1$ when assessed with the Nordbord. ${ }^{36}$ Therefore, considering the initial relative strength scores of the Mid/Post-PHV (4.69N.kg- ${ }^{1}$ ) compared to those of the Pre-PHV EXP group $\left(4.27 \mathrm{~N} . \mathrm{kg}^{-1}\right)$, this may have created a ceiling of adaptation for the more mature individuals, especially with training volume being equated. Indeed, it has been reported that additional loads, such as weighted vests, should be used during the NHE to promote strength increases. ${ }^{40}$ Therefore, although unknown, there may be a certain threshold of eccentric hamstring strength that, once achieved, requires further augmentation to provide sufficient overload. Another potential explanation for this may be that the NHE presented an altered motor control strategy for the Mid/Post-PHV group, which subsequently influenced the performance of the exercise. This is because during the NHE, as the trunk moves forward, the movement becomes progressively uncontrolled due to the shortening of the hamstring moment arm whilst the body mass moment arm lengthens. ${ }^{41}$ Therefore, due to alterations in both upper and lower limb lengths during PHV and accompanying changes in body mass, ${ }^{20}$ it could be plausible that this increases the complexity of the NHE during the growth spurt, which subsequently may impact performance of the exercise. However, this requires further investigation. 
457

458

459

460

461

462

463

464

465

466

467

468

469

470

471

472

473

474

475

476

477

478

479

480

481

482

483

484

485

486

487

488

489

490

491

492

493

494

495

496

497

498

499

500

501

502

This study is not without limitations. Due to the age range of the participants available for this study, it was not possible to include separate Mid-PHV and Post-PHV groups (a combined $\mathrm{Mid} /$ Post group was used). Considering responses to training stimuli can differ between these maturation groups, ${ }^{17,42}$ it would be beneficial to examine such effects in future. In addition, although improvements in eccentric hamstring strength were evident within and between maturation groups, the mechanisms behind such adaptations are unknown. Therefore, future studies could examine the effects of the NHE in youth athletes accounting for changes such as muscle action and muscle architecture, in addition to effect on physical fitness tests such as jumping, sprinting and deceleration.

\section{Practical Applications}

Whilst current guidelines such as the FIFA 11+ provide helpful guidelines for the inclusion of the NHE, the training program used in this study provides a potentially more structured periodised program that can be followed by inexperienced youth athletes. Furthermore, the inclusion of NHE may be utilised with youth male soccer players from the age of 10 years old. Therefore, the inclusion of a low dosage NHE programme, as part of a wellstructured warm prior to soccer training, in male youth players is advised. However, we suggest that technical proficiency in the NHE should be taught prior to its inclusion within the athlete's long-term physical development plan and that the NHE forms part of a holistic strength and conditioning programme that enhances physical fitness in male youth soccer players.

\section{Conclusion}

This is the first study to examine the effects of a NHE program on eccentric hamstring strength in male youth soccer players of different maturation status. Results show the completion of a 6 week NHE provides beneficial increases in eccentric hamstring strength in both Pre-PHV and Mid/Post-PHV players although larger improvements were observed in less mature players. The training program utilised within this study may help practitioners working with male youth soccer players to implement the NHE into their training programmes. 
503

504

505

506

507

508

509

510

511

512

513

514

515

516

517

518

519

520

521

522

523

524

525

526

527

528

529

530

531

532

533

534

535

536

537

538

539

540

541

542

543

544

545

546

547

\section{References}

1. Johnson A, Doherty P, Freemont A. Investigation of growth, development, and factors associated with injury in elite schoolboy footballers: prospective study. BMJ. 2009;338(1):b490.

2. Read PJ, Oliver JL, De Ste Croix MB, Myer GD, Lloyd RS. An audit of injuries in six English professional soccer academies. $J$ Sports Sci. 2018;36(13):1542-1548.

3. Rössler R, Junge A, Chomiak J, Němec K, Dvorak J, Lichtenstein E, Faude O. Risk factors for football injuries in young players aged 7 to 12 years. Scand J Med Sci Sports. 2018;28(3): 1176-1182.

4. Bizzini M, Junge A, Dvorak J. Implementation of the FIFA 11+ football warm up program: how to approach and convince the Football associations to invest in prevention. $\mathrm{Br} J$ Sports Med. 2013;47:803-806.

5. Owoeye OB, Akinbo SR, Tella BA, Olawale OA. Efficacy of the FIFA $11+$ warm-up program in male youth football: a cluster randomised controlled trial. J Sports Sci Med. 2014;13(2), 321328.

6. van Dyk, N., Behan, F. P., \& Whiteley, R. (2019). Including the Nordic hamstring exercise in injury prevention programs halves the rate of hamstring injuries: a systematic review and metaanalysis of 8459 athletes. Br J Sports Med, bjsports-2018.

7. Timmins RG, Bourne MN, Shield AJ, Williams MD, Lorenzen C, Opar DA. Short biceps femoris fascicles and eccentric knee flexor weakness increase the risk of hamstring injury in elite football (soccer): a prospective cohort study. $\mathrm{Br} J$ Sports Med. 2016;50(24):1524-1535.

8. Grooms D, Palmer T, Onate J, Myer G, Grindstaff T. SoccerSpecific Warm-Up and Lower Extremity Injury Rates in Collegiate Male Soccer Players. J Athl Train. 2013;48(6):782-789.

9. van der Horst N, Smits D, Petersen J, Goedhart E, Backx F. The Preventive Effect of the Nordic Hamstring Exercise on Hamstring Injuries in Amateur Soccer Players. Am $J$ Sports Med. 2015;43(6):1316-1323. 
548 10. Gatterer H, Lorenzi D, Ruedl G, Burtscher M. The" FIFA 11+"

549 injury prevention program improves body stability in child (10

550 year old) soccer players. Biology of Sport. 2018;35(2):153-158.

551

552 11. Read PJ, Jimenez P, Oliver J, Lloyd R. Injury prevention in

553 male youth soccer: Current practices and perceptions of

554 practitioners working at elite English academies. J Sports Sci.

555 2018;36(12):1423-1431.

556

557 12. Kilding AE, Tunstall H, Kuzmic D. Suitability of FIFA's "The

558 11" training program for young football players-impact on

559 physical performance. J Sports Sci Med. 2008;7(3):320-326.

560

561 13. Tansel RB, Salci Y, Yildirim A, Kocak S, Korkusuz PF.

562 Effects of eccentric hamstring strength training on lower extremity

563 strength of 10-12 year old male basketball players. Isokinetics and

564 Exercise Science. 2008;16(2):81-85.

565

566 14. Pearson D, Naughton G, Torode M. Predictability of

567 physiological testing and the role of maturation in talent

568 identification for adolescent team sports. J Sci Med Sport.

569 2006;9(4):277-287.

570

571 15. Moran J, Parry D, Lewis I, Collison J, Rumpf M, Sandercock

572 G. Maturation-related adaptations in running speed in response to

573 sprint training in youth soccer players. $J$ Sci Med Sport.

$574 \quad 2018 ; 21(5): 538-542$.

575

576 16. Asadi A, Ramirez-Campillo R, Arazi H, Sáez de Villarreal E.

577 Effects of maturation on jumping ability and sprint adaptations to

578 plyometric training in youth soccer players. $J$ Sports Sci.

579 2018;36(21):2405-2411.

580

581 17. Vera-Assaoka T, Ramirez-Campillo R, Alvarez C, Garcia-

582 Pinillos F, Moran J, Gentil P, Behm B. The effects of maturation

583 on physical fitness adaptations to plyometric drop jump training in

584 male youth soccer players. J Strength Cond Res. IN PRESS.

585

586 18. Moran J, Sandercock, GR, Ramírez-Campillo R, Meylan C,

587 Collison J, Parry DA. A meta-analysis of maturation-related

588 variation in adolescent boy athletes' adaptations to short-term

589 resistance training. J Sports Sci. 2017;35(11):1041-1051.

590

591 19. Moran J, Sandercock G, Ramírez-Campillo R, Wooller JJ,

592 Logothetis S, Schoenmakers PP, Parry DA. Maturation-Related 
593

594

595

596

597

598

599

600

601

602

603

604

605

606

607

608

609

610

611

612

613

614

615

616

617

618

619

620

621

622

623

624

625

626

627

628

629

630

631

632

633

634

635

636

637

638
Differences in Adaptations to Resistance Training in Young Male

Swimmers. J Strength Cond Res. 2018;32(1):139-149

20. Mirwald RG, Baxter-Jones A, Bailey D, Beunen G. An assessment of maturity from anthropometric measurements. Med Sci Sports Exerc. 2002;34(4):689-694.

21. Moran J, Sandercock GR, Ramirez-Campillo R, Todd O, Collinson J, Parry DA. Maturation-related effect of low-dose plyometric training on performance in youth hockey players. Pediatr Exerc Sci. 2017;29(2):194-202.

22. Opar D, Piatkowski T, Williams M, Shield A. A Novel Device Using the Nordic Hamstring Exercise to Assess Eccentric hamstring strength: A Reliability and Retrospective Injury Study. $J$ Orthop Sports Phys Ther. 2013;43(9):636-640.

23. Ramirez-Campillo R, Alvarer C, García-Pinillos F, SanchezSanchez J, Yanci J, Castillo D, Izquierdo M. Optimal reactive strength index: Is it an accurate variable to optimize plyometric training effects on measures of physical fitness in young soccer players? J Strength Cond Res. 2018;32(4), 885-893.

24. Dai Sugimoto GD, Bush HM, Hewett TE. Effects of compliance on trunk and hip integrative neuromuscular training on hip abductor strength in female athletes. J Strength Cond Res. 2014; 28(5), 1187-1194.

25. Freeman BW, Young WB, Talpey SW, Smyth AM, Pane CL, Carlon, TA. The effects of Sprint Training and the Nordic Hamstring Exercise on eccentric hamstring strength and sprint performance in adolescent athletes. $J$ Sports Med Phys. 2019;59(7):1119-1125.

26. Hopkins WG, Marshall S, Batterham A, Hanin J. Progressive Statistics for Studies in Sports Medicine and Exercise Science. Med Sci Sports Exerc. 2009;41(1):3-13.

27. Spencer M, Fitzsimons M, Dawson B, Bishop D, Goodman C. Reliability of a repeated-sprint test for field-hockey. J Sci Med Sport. 2006;9(1-2):181-184.

28. Hopkins WG. A Spreadsheet for Deriving a Confidence Interval, Mechanistic Inference and Clinical Inference from a P Value. Sportscience. 2007;11:16-20. 
639

640

641

642

643

644

645

646

647

648

649

650

651

652

653

654

655

656

657

658

659

660

661

662

663

664

665

666

667

668

669

670

671

672

673

674

675

676

677

678

679

680

681

682

683
29. Mjølsnes R, Arnason A, Østhagen T, Raastad T, Bahr R. A 10 -week randomized trial comparing eccentric vs.. concentric hamstring strength training in well-trained soccer players. Scand $J$ Med Sci Sports. 2004;14(5):311-317.

30. Iga J, Fruer CS, Deighan M, Croix MDS, James DVB. 'Nordic' hamstrings exercise-engagement characteristics and training responses. Int J Sports Med. 2012;33(12):1000-1004.

31. Lovell R, Knox M, Weston M, Siegler JC, Brennan S, Marshall PW. Hamstring injury prevention in soccer: Before or after training? Scand J Med Sci Sports. 2018;28(2):658-666.

32. Delahunt E, McGroarty M, De Vito G, Ditroilo M. Nordic hamstring exercise training alters knee joint kinematics and hamstring activation patterns in young men. Eur J Appl Physiol. 2016;116(4):663-672.

33. Lacome M, Avrillon S, Cholley Y, Simpson BM, Guilhem G, \& Buchheit M. Hamstring Eccentric Strengthening Program: Does Training Volume Matter? Int J Sports Physiol Perform. 2019; 1(aop), 1-27.

34. Deli CK, Fatouros IG, Paschalis, V, Georgakouli K, Zalavras A, Avloniti A, Jamurtas AZ. A Comparison of exercise-induced muscle damage following maximal eccentric contractions in men and boys. Pediatr Exerc Sci. 2017;29(3): 316-325.

35. Chen TC, Chen HL, Liu YC, Nosaka K. Eccentric exerciseinduced muscle damage of pre-adolescent and adolescent boys in comparison to young men. Eur J Appl Physiol. 2014;114(6): 11831195 .

36. Buchheit M, Cholley Y, Nagel M, Poulos N. The effect of body mass on eccentric hamstring strength assessed with an instrumented nordic hamstring device (Nordbord) in football players. Int J Sports Physiol Perform. 2016;11(6): 721-726.

37. Meylan CMP, Cronin JB, Oliver JL, Hopkins WG, Contreras B. The effect of maturation on adaptations to strength training and detraining in 11-15-year-olds. Scand J Med Sci Sports 2014;24(3):156-164. 
684 38. Rumpf MC, Cronin JB, Mohamad IN, Mohamad S, Oliver JL, 685 Hughes MG. The effect of resisted sprint training on maximum 686 sprint kinetics and kinematics in youth. EUR J Sport Sci. 687 2015;15(5): 374-381.

689 39. Read P, Oliver JL, De Ste Croix MB, Myer GD, Lloyd RS. 690 Landing Kinematics in Elite Male Youth Soccer Players of 691 Different Chronologic Ages and Stages of Maturation. J Athl 692 Train. 2018;53(4):372-378.

693

694 40. Pollard CW, Opar DA, Williams MD, Bourne MN, Timmins

695 RG. Razor hamstring curl and Nordic hamstring exercise 696 architectural adaptations: Impact of exercise selection and 697 intensity. Scand J Med Sci Sports. 2019;29(5):706-715.

698

699 41. Monajati A, Larumbe-Zabala E, Goss-Sampson M, Naclerio F. 700 Analysis of the hamstring muscle activation during two injury 701 prevention exercises. J Hum Kinet. 2017;60(1): 29-37.

702

703 42. Moran J, Sandercock GR, Ramírez-Campillo R, Meylan CM, 704 Collison JA, Parry DA. Age-related variation in male youth 705 athletes' countermovement jump after plyometric training: a meta706 analysis of controlled trials. J Strength Cond Res. 2017;31(2): 552707565. 
Table 1. Participants characteristics (mean [SD])

\begin{tabular}{cccccccc}
\hline $\begin{array}{c}\text { Maturation } \\
\text { Status }\end{array}$ & Group & Number & $\begin{array}{c}\text { Age } \\
(\mathrm{yrs})\end{array}$ & $\begin{array}{c}\text { Standing Height } \\
(\mathrm{cm})\end{array}$ & $\begin{array}{c}\text { Seated Height } \\
(\mathrm{cm})\end{array}$ & $\begin{array}{c}\text { Body Mass } \\
(\mathrm{kg})\end{array}$ & $\begin{array}{c}\text { PHV Offset } \\
(\mathrm{yrs})\end{array}$ \\
\hline Pre-PHV & EXP & 8 & $11.0 \pm 0.9$ & $144.2 \pm 4.4$ & $71.5 \pm 2.0$ & $37.7 \pm 2.8$ & $-2.8 \pm 0.3$ \\
& CON & 11 & $10.9 \pm 0.8$ & $147.2 \pm 4.4$ & $72.5 \pm 3.0$ & $40.3 \pm 4.1$ & $-2.7 \pm 0.5$ \\
\hline Mid/Post-PHV & EXP & 16 & $14.0 \pm 1.1$ & $172.3 \pm 7.0$ & $84.6 \pm 3.4$ & $61.8 \pm 6.3$ & $0.4 \pm 0.9$ \\
& CON & 13 & $13.7 \pm 1.0$ & $171.9 \pm 8.3$ & $85.1 \pm 4.3$ & $59.5 \pm 8.3$ & $0.1 \pm 0.8$ \\
& & & & & & & \\
\end{tabular}

Note: PHV: Peak height velocity; EXP: Experimental; CON: Control. 
Table 2. 6 week nordic hamstring exercise training programme.

\begin{tabular}{cccc}
\hline Week & Frequency & Prescription & Total Weekly Volume \\
\hline 1 & 1 & $2 \times 5$ & 10 \\
2 & 2 & $2 \times 5$ & 20 \\
3 & 2 & $2 \times 6$ & 24 \\
4 & 2 & $3 \times 6(\mathrm{~S} 1), 2 \times 6(\mathrm{~S} 2)$ & 30 \\
5 & 2 & $3 \times 6$ & 36 \\
6 & 2 & $3 \times 8(\mathrm{~s} 1), 3 \times 6(\mathrm{~S} 2)$ & 42 \\
\hline
\end{tabular}

Note: $\mathrm{S} 1$ : session $1 ; \mathrm{S} 2$ : session 2. 
Table 3: Within-group analysis for pre and post scores, effect sizes (ES) with $90 \%$ confidence intervals, $\%$ outcome of likelihood effect is beneficial, trivial or harmful and odds ratio for eccentric hamstring strength normalised to body mass (N.kg-1)

\begin{tabular}{|c|c|c|c|c|c|c|c|c|}
\hline Pre-PHV & Pre $($ N.kg-1) & Post (N.kg-1) & ES (90\% CI) & ES Descriptor & Beneficial & Trivial & Harmful & Odds Ratio \\
\hline $\operatorname{EXP}(n=8)$ & $4.27 \pm 0.88$ & $4.95 \pm 0.76$ & $0.83(0.03-1.68)$ & Moderate & Likely $(90.3 \%)$ & Unlikely $(7.1 \%)$ & Very Unlikely $(2.6 \%)$ & 357 \\
\hline $\operatorname{CON}(n=11)$ & $4.24 \pm 0.83$ & $4.20 \pm 0.70$ & $-0.05(-0.75-0.65)$ & Trivial & Most Unlikely (0\%) & Most Likely (100\%) & Most Unlikely ( $0 \%)$ & 0 \\
\hline Mid/Post-PHV & Pre $\left(\right.$ N.kg $\left.^{-1}\right)$ & Post $\left(\mathrm{N} . k g^{-1}\right)$ & ES $(90 \%$ CI) & ES Descriptor & Beneficial & Trivial & Harmful & Odds Ratio \\
\hline $\operatorname{EXP}(n=16)$ & $4.69 \pm 0.85$ & $5.17 \pm 0.95$ & $0.53(-0.06-1.12)$ & Small & Likely $(85.4 \%)$ & Unlikely $(13.2 \%)$ & Very Unlikely (1.4\%) & 397 \\
\hline $\operatorname{CON}(n=13)$ & $4.45 \pm 0.69$ & $4.43 \pm 0.72$ & $-0.03(-0.67-0.20)$ & Trivial & Most Unlikely (0\%) & Most Likely (100\%) & Most Unlikely (0\%) & 0 \\
\hline
\end{tabular}


Table 4: Between-group analysis for pre and post scores, effect sizes (ES) with $90 \%$ confidence intervals, $\%$ outcome of likelihood effect is beneficial, trivial or harmful and odds ratio for eccentric hamstring strength normalised to body mass $\left(\mathrm{N} . \mathrm{kg}^{-}{ }^{1}\right)$

\begin{tabular}{|c|c|c|c|c|c|c|c|}
\hline Variable & Group & ES & ES Descriptor & Beneficial & Trivial & Harmful & $\begin{array}{l}\text { Odds } \\
\text { Ratio }\end{array}$ \\
\hline \multirow{2}{*}{$\begin{array}{l}\text { Relative peak force } \\
\qquad\left(\mathrm{N}^{\left.-\mathrm{kg}^{-1}\right)}\right.\end{array}$} & $\begin{array}{l}\text { Pre-PHV EXP vs } \\
\text { Pre-PHV CON }\end{array}$ & $1.03(0.23-1.84)$ & Moderate & Likely (91.1\%) & Unlikely $(6.3 \%)$ & Very Unlikely $(2.6 \%)$ & 373 \\
\hline & $\begin{array}{l}\text { Mid/Post-PHV EXP vs } \\
\text { Mid/Post-PHV CON }\end{array}$ & $0.87(0.22-1.51)$ & Moderate & Likely $(89.9 \%)$ & Very Unlikely (7.8\%) & Very Unlikely $(2.3 \%)$ & 384 \\
\hline
\end{tabular}

